\title{
Logística reversa de embalagens vazias de agrotóxicos e as dificuldades para efetiva
}

\section{implantação}

\author{
Reverse logistics of empty pesticides packaging and the difficulties for effective implementation \\ Logística inversa del embalaje de pesticidas vacíos y las dificultades para una implementación
}

efectiva

\author{
Karine Pires Cremasco Aragos \\ ORCID: https://orcid.org/0000-0002-8441-4811 \\ Universidade Estadual Paulista, Brasil \\ E-mail: karine.cremasco@unesp.br \\ Luís Roberto Almeida Gabriel Filho \\ ORCID: https://orcid.org/0000-0002-7269-2806 \\ Universidade Estadual Paulista, Brasil \\ E-mail: gabriel.filho@unesp.br \\ Sérgio Silva Braga Junior \\ ORCID: https://orcid.org/0000-0002-4979-1988 \\ Universidade Estadual Paulista, Brasil \\ E-mail: sergio.braga@unesp.br
}

\section{Resumo}

O Brasil possui uma farta produtividade agrícola e com isso, há um crescente uso de defensivos agrícolas, Todavia, muitas vezes, não há o adequado descarte das embalagens vazias deste defensivo, acarretando assim, uma interferência negativa direta no meio ambiente. Em razão de tais fatos, foi implementado a logística reversa, a fim de solucionar o problema de degradação ambiental acarretado pelos descartes indevidos das referidas embalagens. Apesar de todo aparatos legislativo, verifica-se que a logística reversa não funciona em sua integralidade. Assim, no presente trabalho, são feitas algumas análises sobre os principais problemas para implantação efetiva de uma logística reversa de embalagens vazias de agrotóxicos. Para tanto, partese de uma pesquisa bibliográfica que busca montar o substrato teórico usado na análise do problema a partir da análise e algumas pesquisas empíricas realizadas em algumas regiões do Brasil e da análise da legislação pertinente. Foi possível constatar que os principais empecilhos para logística reversa está na omissão da lei, na burocratização, falta de estrutura tanto dos produtores rurais, quanto dos demais agentes da cadeia do agronegócio e, por fim, na falta de uma fiscalização rigorosa por parte do poder público. A solução demonstrada pelos autores das pesquisas empíricas foi de uma reanalise da legislação, bem como das estruturas impostas a conscientização ambiental a partir de uma educação pertinente a esse ponto é fundamental para facilitar a implantação efetiva de logística reversa de embalagens vazias de agrotóxicos no Brasil.

Palavras-chave: Logística reversa; Agrotóxicos; Meio Ambiente; Desenvolvimento Sustentável.

\begin{abstract}
Brazil has an abundant agricultural productivity and as a result, there is an increasing use of agricultural pesticides. Howe ver, many times, there is not an adequate disposal of the empty packaging of this pesticide, thus causing direct negative interference in the environment. As a result of these facts, reverse logistics was implemented in order to solve the problem of environmental degradation caused by the improper disposal of said packaging. Despite all legislative mechanisms, it appears that reverse logistics does not work in its entirety. Thus, in the present work, some analyzes are made about the main problems for the effective implementation of reverse logistics of empty pesticide packaging. To do so, it starts from a bibliographic research that seeks to assemble the theoretical substrate used in the analysis of the problem from the analysis and some empirical research carried out in some regions of Brazil and the analysis of the relevant legislation. It was possible to verify that the main obstacles to reverse logistics are the omission of the law, bureaucratization, lack of structure for both rural producers and other agents in the agribusiness chain and, finally, the lack of strict inspection by the government. public. The solution shown by the authors of the empirical research was to reanalyze the legislation, as well as the structures imposed on environmental awareness based on an education relevant to this point, which is fundamental to facilitate the effective implementation of reverse logistics of empty pesticide packaging in Brazil.
\end{abstract}

Keywords: Reverse logistic; Pesticides; Environment; Sustainable development. 


\section{Resumen}

Brasil tiene una productividad agrícola abundante y como resultado, hay un uso creciente de plaguicidas agrícolas, sin embargo, muchas veces, no hay una disposición adecuada de los envases vacíos de este plaguicida, provocando una interferencia negativa directa en el medio ambiente. Como resultado de estos hechos, se implementó la logística inversa con el fin de solucionar el problema de degradación ambiental provocado por la disposición inadecuada de dichos envases. A pesar de todos los mecanismos legislativos, parece que la logística inversa no funciona en su totalidad. Así, en el presente trabajo se realizan algunos análisis sobre los principales problemas para la implementación efectiva de la logística inversa de envases vacíos de plaguicidas. Para ello, se basa en una investigación bibliográfica que busca ensamblar el sustrato teórico utilizado en el análisis del problema a partir del análisis y algunas investigaciones empíricas realizadas en algunas regiones de Brasil y el análisis de la legislación pertinente. Se pudo constatar que los principales obstáculos para la logística inversa son la omisión de la ley, la burocratización, la falta de estructura tanto para los productores rurales como para otros agentes de la cadena agroindustrial y, finalmente, la falta de fiscalización estricta por parte del gobierno. La solución mostrada por los autores de la investigación empírica fue volver a analizar la legislación, así como las estructuras impuestas a la conciencia ambiental a partir de una educación relevante en este punto, fundamental para facilitar la implementación efectiva de la logística inversa de envases vacíos de plaguicidas en Brasil.

Palabras clave: Logística inversa; Plaguicidas; Medio ambiente; Desenvolvimiento sustentable.

\section{Introdução}

O Brasil é um dos maiores utilizadores de agrotóxicos do planeta e, devido a isso, a quantidade utilizada causa muitos danos ao meio ambiente (Borsoi et al., 2014). O uso de agrotóxicos começou a se intensificar na década de 1950 com a chamada Revolução Verde, que foi uma mudança radical no mundo agroindustrial. Os agrotóxicos auxiliam na melhoria do desempenho produtivo, mesmo que envolvam riscos ambientais e humanos (Sehnem et al., 2009). Desde então, ocorreram algumas modernizações e novas tecnologias no que diz respeito ao uso de agrotóxicos e ao cultivo de alimentos.

Em razão de tais fatos, o que se percebeu é uma quantidade grande de produtos de agrotóxicos sendo destinados aos produtores e/ou agricultores, sem haver o descarte correto destas embalagens, com isso, há uma interferência negativa não só ao meio ambiente como a população em modo geral.

Por isso foi criado o sistema da logística reversa, sendo este um mecanismo de retiradas das embalagens das propriedades, tendo o seu destino final correto e devidamente sustentável.

Para isso foi criado o Instituto Nacional de Processamento de Embalagens Vazias - INPEV, responsável pela gestão dessa cadeia reversa no Brasil. Cumpre destacar que o INPEV é uma instituição sem fins lucrativos, que foi criada no ano de 2001 com sua atividade a partir de 2002. Trata-se de uma instituição que representa a indústria para defensivos agrícolas, no que se refere a responsabilização sobre o destino de embalagens vazias dos seus produtos, conformando-se a Lei 9974 de 2020 , junto com o Decreto 4074 de 2002. A primeira atribui a cada elo da cadeia uma respectiva responsabilização para que o sucesso seja garantido em relação a destinação final.

A construção de uma estratégia de logística reversa demanda uma estrutura peculiar para que se garanta o fluxo reverso dos materiais e das informações de uma maneira eficiente, com custos menores possíveis e com rentabilidade também maior possível. Conforme as informações da INPEV ${ }^{1}$, já entre 2012 e 2007 investiu na cadeia 192 milhões de reais. Sendo que deste valor 42 milhões aos distribuidores, agricultores, revendas de agrotóxicos, associações e cooperativas de agricultores. 150 milhões couberam os fabricantes dos produtos. Naquela época já se apontava de forma clara a conscientização sobre que ainda era necessário evoluir muito em relação a esta cadeia e sua implementação. E isso não só sobre a eficiência em relação ao volume recolhido ou sobre a diminuição das embalagens contaminadas, mas antes de tudo para se tornar uma cadeia cada vez mais autosustentável.

${ }^{1}$ INPEV - Instituto Nacional de Processamento de Embalagens Vazias. Disponível em: https://inpev.org.br/index. Acesso em: 05/02/2021. 
Research, Society and Development, v. 10, n. 2, e52210212921, 2021

(CC BY 4.0) | ISSN 2525-3409 | DOI: http://dx.doi.org/10.33448/rsd-v10i2.12921

O INPEV é uma instituição que opera no sentido da promoção da sustentabilidade dessa cadeia. Dentro desse contexto surge a seguinte pergunta: quais os principais desafios para implantação de uma logística reversa aplicada ao recolhimento de embalagens de agrotóxicos? Esse artigo busca exatamente responder esta questão com alguns apontamentos teóricos a partir da análise de algumas pesquisas empíricas realizadas por alguns autores no Brasil.

A importância do assunto aqui tratado nesse artigo está na necessidade de uma contribuição para a reflexão sobre logística reversa, de um lado, e sobre esta mesma logística quando aplicada ao universo dos agrotóxicos e suas embalagens. Contribui para administração de empresas a partir dos avanços na reflexão, contribui para os agricultores ratificando ações que tem tido sucesso e modificando ações não profícuas para a cadeia. Contribui também para fabricantes em relação ao reconhecimento do esforço realizado e para sociedade em geral na medida em que ajuda a pensar formas de desenvolvimento sustentável.

\section{Metodologia}

Trata-se de uma pesquisa de caráter qualitativo, com estudo de natureza exploratória, levantamento de normas e legislações a respeito da logística reversa, bem como levantamento bibliográfico a fim de avaliar a eficácia da logística reversa de embalagens vazias de agrotóxicos.

É sabido que uma pesquisa de caráter qualitativo tem como finalidade a exploração de um fenômeno que segundo Creswell (2010), a finalidade é analise de um fenômeno para desenvolver uma teoria.

De acordo com Ludke e Andre (2013), a pesquisa qualitativa possui características na qual demonstra que o pesquisador é o instrumento principal, uma vez que os dados principais são descritivos, a análise dos dados geralmente decorre de um processo indutivo, dentre outros.

Convém destacar ainda que, de acordo com Pereira (2018), é primordial a interpretação do autor no seu levantamento bibliográfico. Deste modo, resta claro e evidente que o tema objeto da presente pesquisa se refere à uma metodologia qualitativa, uma vez que se utiliza de levantamentos bibliográficos e análises de legislações, a fim de analisar a eficácia da logística reversa de embalagens vazias de agrotóxicos.

\section{Logística reversa}

Seguindo as diretrizes das Leis $\mathrm{n}^{\circ} 12.305$ / 2010, a PNRS se constitui como um processo que pode mitigar os principais problemas gerados pelo excesso de resíduos recolhidos por órgãos específicos ou deixados em espaços públicos. Esta é, sem dúvida, uma maneira mais profícua e correta de, em última instância, descartar resíduos sólidos de uma variedade de materiais, especialmente produtos que são prejudiciais ao meio ambiente.

Para Carvalho (2005), a logística reversa faz parte de uma cadeia de suprimentos que planeja, implementa e controla o fluxo de armazenagem eficiente e econômico de matérias-primas, produtos semiacabados, acabados e informações relacionadas. Isto do ponto de partida ao ponto de consumo com o objetivo de atender às necessidades do cliente (Carvalho, 2005).

Para Carvalho (2005), a logística tem melhorado ao longo do tempo, buscando melhorar o atendimento, transporte, armazenamento e distribuição, reduzindo perdas, minimizando distâncias e tanto financeira quanto funcionalmente para a empresa, aumentando meu faturamento. Também contribui com o meio ambiente, removendo a maior parte dos resíduos que podem ser prejudiciais ao meio ambiente e à vida de plantas e animais. Segundo Leite (2009), Logística Reversa é Planejar, operar e controlar as informações logísticas correspondentes com o fluxo de devoluções de produtos pós-venda e pós-consumo 
para o ciclo de negócios, um domínio da logística empresarial. Agrega vários tipos de valor por meio de ciclos de produção, canais de distribuição reversos: econômicos, de serviços, ecológicos, jurídicos, logísticos, imagem corporativa etc (Leite, 2010).

Carvalho (2005) e Leite (2010) constataram que a logística reversa é um processo importante para a indústria reduzir custos de produção e remover resíduos que podem prejudicar o ciclo biológico e o meio ambiente, portanto, acre ditamos que seja benéfica ao meio ambiente. É importante para a classe social menos favorecida, que vive da venda de produtos retirados do lixo.

Segundo Rogers e Tibben-Lembke (1998), a logística reversa foi adquirida para a definição esperada de ações ou intenções, a execução e controle dos fluxos de matéria-prima, o armazenamento dos materiais planejados, a saída dos processos de produção e, consequentemente de um processo de informação para o reconhecimento dos clientes. Todos esses são destinados à reinserção de valor ou destinação adequada. Existem vários motivos pelos quais um produto não é consumido ou é devolvido ao fornecedor após a venda. Segundo Leite (2010), podemos classificá-los em três grandes grupos.

$\mathrm{O}$ primeiro se deve a razões comerciais, incluindo erros de embarque, falta de estoque, remessa, sazonalidade e lançamento de novos modelos. O mesmo é verdadeiro para grupos defeituosos. Neste grupo, a empresa garante a reparação ou substituição de peças. Semelhante a um grupo de produtos com data de validade.

Lacerda (2002) salienta a radicalidade da logística reversa no processo produtivo da empresa. Firma que investir nessas práticas tem gerado retornos positivos, mas para garanti-los vários fatores precisam ser organizados, entre eles: (1) delimitação de forma correta dos contextos dos materiais que faltam para empresa buscando possibilitar o fluxo reverso está ligado a recondicionamento e revenda assim como reciclagem e descarte. (2) A padronização e o mapeamento dos processos possibilitam a continuidade da logística reversa. Não deve ser uma ocorrência rara. Os procedimentos precisam ser formalizados para garantir o gerenciamento e a melhoria. (3) Planejamento da rede de logística para se adequar ao fluxo de entrada e saída de materiais, é necessário planejar a infraestrutura do processo de logística reversa. (4) Estabelecer relações entre clientes e fornecedores: este processo deve ser mutuamente benéfico.

Segundo Brito et al (2005), os procedimentos e recursos disponíveis para realizar as operações de transporte, armazenamento dos produtos de uma empresa estão diretamente relacionados ao nível organizacional da logística, a gestão de estoques, sistemas de informação e outros pontos. Brito et al (2005) criaram uma matriz estruturada de canal reverso onde enfatizam pontos estratégicos para que o planejamento seja feito com procedimentos adequados de devolução de produtos. Os autores da lista a seguir sugerem que os pontos abordados devem ser utilizados para medir o nível organizacional do canal reverso de empresas em diferentes unidades de negócios para devolução do produto.

1. PROCEDIMENTOS GERAIS: Os procedimentos para retornos bem definidos. Controles relacionada o recebimento de retorno. Qualificação do retorno e sua classificação. Qualificação através de controles para o retorno. Criação de procedimento eficaz para consolidar o retorno. E o procedimento para selecionar o destino definido (Brito et al, 2005).

2. TRANSPORTE: os meios e os veículos definidos. A frequência da coleta e seu trajeto bem definido. Acondicionamento definido para o retorno. O grau de prioridade do retorno. O controle de custos de transporte (Brito et al, 2005).

3. CONTRATOS: contratos relacionados junto a cadeia de terceiros contratados para revalorização. Pagamentos e ressarcimentos (Brito et al, 2005).

4. ARMAZENAGEM E RECURSO: as áreas delimitadas para destinação do retorno. As destinadas a remanufaturada. Controle de custos para armazenagem do retorno. Recursos humanos para o retorno. Equipamentos. Sistemas de informações (Brito et al, 2005). 
5. REVALORIZAÇÃO: Motivação para o tratamento. Ganho de imagem. Recuperação de valor. Receita e custo conhecido. Mercado secundário (Brito et al, 2005).

6. Fluxo de informações: sistema de informação para retorno. Operações informatizadas. As informações tendem a alimentar diversos outros espaços (Brito et al, 2005).

Entendendo a logística reversa com base nos conceitos de Carvalho (2005) e Leite (2010), percebe-se que seus principais aspectos dizem respeito a várias áreas ao mesmo tempo: fornecedores de matéria-prima, produtores, centros de distribuição, consumidores. Essas ações estão inter-relacionadas e incluem o fornecimento de matérias-primas utilizadas na indústria para a fabricação de diversos produtos produzidos de acordo com as necessidades e perspectivas do consumidor. Os produtos são então distribuídos e armazenados, que são colocados à disposição dos consumidores. Leite (2005) também revela que a logística reversa pode ser dividida em duas etapas principais, a saber, pós-venda e pós-consumo. Para o autor, a logística reversa de pós-venda visa equilibrar e operar o fluxo físico e as informações logísticas associadas a produtos pós-venda não utilizados ou raramente utilizados. Eles fazem parte do canal reverso pelo qual esse produto flui. Tem como objetivo agregar valor aos produtos logísticos devolvidos ao fabricante ou fornecedor.

Para Leite (2005), o canal de pós-venda se preocupa principalmente com a indústria e os revendedores. Esses são relacionamentos quase sem consumidor, e os próprios revendedores voltam aos produtos de fábrica com defeito que são obsoletos ou não alcançam o propósito pretendido. Por algum modo, esses produtos devem ser devolvidos ao local de origem para o descarte adequado.

Na verdade, como no caso do comércio online, a logística reversa do pós-venda que envolve o consumidor ainda tem muitas falhas, lacunas no processo, canais, infraestrutura e principalmente confiabilidade. A relação entre a fábrica e o consumidor nem sempre se concretiza e atende amplamente as necessidades do comprador. O tema principal deste artigo, consiste em uma ampla gama de processos que podem operar o fluxo físico de bens de consumo descartados para fins úteis e convertê-los em outros produtos. Trata-se de um processo de reciclagem para reaproveitar produtos junto aos consumidores e encaminhá-los para a indústria. É um processo complexo que se desenvolve lentamente ou de forma fragmentada porque depende da atitude da população, mas no caso em comento, depende ada atitude principal do produtor rural.

Segundo Leite (2005), a logística pós-consumo pode ser dividida em três subsistemas. Reutilizar quando o produto retornar ao consumidor. O uso original é o mesmo, mas rotulado como comumente usado. Remanufatura quando as peças defeituosas de um produto são substituídas e, por fim, reciclagem, na qual as peças do produto são descartadas e utilizadas como matéria-prima para a fabricação de novos produtos. Para Liva et al (2003), existem três tipos de logística reversa: pósvenda, pós-consumo e logística reversa de embalagens.

De acordo com o autor acima citado, a primeira se refere ao fluxo logístico ligado a bens de pós venda que pode ou não ter uso por algum motivo e que por isso são devolvidos. Isso ocorre por um erro no processamento do pedido defeito de fabricação do produto ou defeitos no transporte. Esses produtos precisam ser retornados para o ciclo de negócios agregando valor para empresa o mesmo simplesmente para reciclagem o reaproveitamento. A segunda responde ao fluxo físico de bens de consumo e resíduos industriais descartados pela sociedade e indústria, e tem uma vida útil próxima à dos produtos finais ou usados que podem ser reaproveitados no ciclo produtivo ou comercial. Esses produtos pós-consumo podem ser provenientes de bens de consumo duráveis ou descartáveis que são reaproveitados. Após a desmontagem do produto, as peças podem ser reutilizadas, remanufaturadas e recicladas. Se nenhuma dessas possibilidades for atendida, o produto deve ter a destinação final correta em aterro, lixão ou incineração. 
A logística reversa de embalagens também pode ser interpretada a partir do conceito de logística inversa após o consumo ou pós-venda. Com o aumento da distribuição para ambientes de mercado cada vez mais distantes, os custos de embalagem estão aumentando. Ao mudar o tipo de produto e sua distribuição, são utilizadas embalagens primárias, secundárias, terciárias, quaternárias e até de quinto nível. Devido a essa realidade, as empresas optaram por utilizar embalagens retornáveis ou reutilizáveis, dado o aumento significativo de resíduos perigosos para o meio ambiente a cada ano.

\section{Agrotóxicos, Embalagens e Meio Ambiente}

Como dito anteriormente, o Brasil é um dos maiores utilizadores de agrotóxicos do planeta e, devido a isso, a quantidade utilizada causa muitos danos ao meio ambiente (Borsoi et al., 2014). O uso de agrotóxicos começou a se intensificar na década de 1950 com a chamada Revolução Verde, que foi uma mudança radical no mundo agroindustrial. Os agrotóxicos auxiliam na melhoria do desempenho produtivo, mesmo que envolvam riscos ambientais e humanos (Sehnem et al., 2009). Desde então, ocorreram algumas modernizações e novas tecnologias no que diz respeito ao uso de agrotóxicos e ao cultivo de alimentos.

Segundo a $\mathrm{ABNT}^{2}$, a embalagem de agrotóxicos é considerada um tipo perigoso da classe 1 pela NBR 10.004 / 87. Em relação às embalagens duras lavadas, foi elaborado um projeto de padronização que hoje é considerado inofensivo no armazenamento, transporte e manuseio. O projeto de padronização foi aprovado pela ABNT. A intoxicação humana causada por pesticidas pode ocorrer na forma aguda (se o efeito aparecer 24 horas após a exposição), subaguda (o efeito aparece dentro de dias ou semanas) ou na forma crônica (efeito tardio). O efeito depende de fatores como tempo de exposição, padrão de contato, dose absorvida pelo organismo, propriedades do agrotóxico e estado de saúde da pessoa infectada (Brasil, 2014).

Os principais fatores de risco para a saúde dos agricultores são a falta de uso de equipamentos de proteção individual (EPI), falta de estrutura não só física dos estabelecimentos comerciais, como também econômica, a escolaridade e a destinação final das embalagens (Soares; Freitas; Coutinho, 2005). Estudo de Schmidt e Godinho (2006) em uma cooperativa do estado de São Paulo aponta falha na destinação final das embalagens vazias, com relatos de agricultores que queimam embalagens e reaproveitam para outros fins. O principal problema encontrado na pesquisa é, a falha na estrutura que a logística reversa impõe, bem como a oneração das condutas ao hipossuficiente da cadeia, que é o produtor rural. Os autores exigem maiores incentivos do governo para uma estrutura da logística reversa que não onere os produtores rurais, que em sua grande maioria são de pequena propriedade, não tendo quaisquer condições de arcar com as obrigações impostas pela lei.

Estudo realizado por Abreu e Alonzo (2016) no município de Lavras-MG alerta para incompatibilidade na implantação do chamado uso seguro de agrotóxicos no contexto da agricultura familiar da região. Em relação às embalagens dos agrotóxicos, foi apontado que não há recepções de embalagens vazias suficientes. Apesar do foco no aumento da educação ambiental e da educação escolar para os agricultores familiares, a complexidade e o custo das medidas de segurança de agrotóxicos sugerem que o uso seguro pelos pequenos agricultores tem sido inviável.

Após avaliar a relação entre o contato com pesticidas e surtos de doenças, concluiu-se que o contato com pesticidas aumenta a probabilidade de síndromes dolorosas, como o desenvolvimento de distúrbios neurológicos e doenças degenerativas do sistema nervoso central. O estudo também relatou aumento de intoxicações agudas e doenças que afetam a pele, os olhos e o trato respiratório (Souza et al., 2011).

\footnotetext{
${ }^{2}$ Associação Brasileira de Normas Técnicas (ABNT): Recuperado de: https://sinir.gov.br/index.php/component/content/article/2-uncategorised/124embalagens-de-agrotoxicos\#: :text=A\%20norma\%20t\%C3\%A9cnica\%20NBR\%2013968,concentra\%C3\%A7\%C3\%B5es\%20e\%20reutilizados\% 20 na \%20lavoura.
} 
O fator mais influente considerado pelos agricultores para a devolução das embalagens de agrotóxicos é a lei (Ladeira; Maehler; Nascimento, 2012).

Os documentos legais de nível nacional e internacional estão listados abaixo.

A Lei $n^{\circ} 7.802 / 1989$ foi um marco importante na redução do impacto ambiental dos agrotóxicos. Isso porque a lei do Brasil incentivava a compra desses produtos, como o Decreto 24.114 de 1934. As leis de agrotóxicos foram alteradas pela Lei 9.974 no ano de 2000 e regulamentadas pelo Decreto Federal 4.074 no ano de 2002. A Lei 9.974 exige que a responsabilidade seja compartilhada entre todos os elos do sistema do ciclo de vida da embalagem (inpEV, 2017). Além da Lei de Produtos Químicos Agrícolas, a RESOLUÇÃO CONAMA n 465 de 2014 discute licenças ambientais para instalações que recebam embalagens de agrotóxicos e muito mais.

A forma principal ferramenta operacionais da pela Lei 9.974/00, que impõe a responsabilidade compartilhada entre integrantes da cadeia do agronegócio, para exercer as funções da forma seguinte: para os agricultores, é obrigação, efetuar a tríplice lavagem, guardar em local seguro e adequado e após proceder a devolução das embalagens para o estabelecimento comercial onde foram compradas, no prazo de até um ano após a compra. (BRASIL,2000)

No tocante a tríplice lavagem conforme norma tesar ação da $\mathrm{ABNT}^{3}$. Deve armazenar em sua propriedade de forma adequada e não utilizar as embalagens para outros fins que não a sua finalidade padrão. Devem também guardar o comprovante da entrega da embalagem.

Em relação ao recebimento destas embalagens pelos comerciantes, estes devem receber e igualmente armazenar de forma adequada até que a fábrica ou autorizado efetuar a retirada.

Ainda cabe ao comerciante, no momento da venda, mostrar todos os procedimentos necessários para que se devolva, se destine e transporte, assim como, emitir comprovantes para o agricultor contendo a nota fiscal e documentos da devolução com data de recebimento e quantidades e tipos de embalagem recebidas.

No caso do poder público este deve fiscalizar a devolução adequada conforme as normas para embalagens vazias. Deve também monitorar o armazenamento, reciclagem, transporte, reuso das embalagens vazias. Devem licenciar as unidades de recebimento. Devem ser participantes da conscientização ambiental junto a comerciantes e produtores de agrotóxicos acerca da destinação das embalagens após o uso.

Por parte dos fabricantes, a sua obrigação é efetuar a retirar das embalagens vazias recebidas e destinar para reciclagem incineração conforme o caso adequado em relação a cada tipo de embalagem. A Lei $7802 / 1989$ impõe algumas penas de natureza administrativa, penal e civil para quebra das obrigações legais de cada um dos elos da cadeia supracitada.

Pesquisas de Marques et al (2015) concluíram que a cooperação de todos os envolvidos no processo, a divulgação de campanhas educativas e a maior participação dos governos são os fatores mais relevantes para o cumprimento da legislação. Os autores também argumentam que os agricultores muitas vezes têm dificuldade em cumprir a lei, especialmente quando se trata de recolher e transportar embalagens. Com isso, além da maior fiscalização e prestação de informações por parte do governo, foi necessário um melhor suporte funcional em toda a área agrícola, e todos os participantes da cadeia logística participaram do processo de logística reversa de embalagens, resultando em contribuições para a preservação do meio ambiente.

Os países da União Europeia, assim como a Islândia, a Noruega e o Liechtenstein, devem cumprir os Regulamentos de Classificação, Rotulagem e Embalagem (CLP) do Regulamento (CE) No 1272/2008. Cada país tem leis ligeiramente

\footnotetext{
${ }^{3}$ INPEV - Recuperado em 10/01/2021, de https://www.inpev.org.br/relatorio_anual/2010/port/ra/02.htm\#: :text=incineradoras)-,Respon sabili dade \%20compartilhada,ind\%C3\%BAstria\%20fabricante\%20e $\% 20$ poder\%20p\%C3\%BAblico.
} 
diferentes dos outros (EUROPA, 2017). O CLP funciona da mesma forma que a legislação brasileira, compartilhando responsabilidades entre fabricantes, distribuidores e compradores, cada um com suas próprias obrigações. A União Europeia implementou o Sistema Globalmente Harmonizado (GHS), um regulamento desenvolvido pelas Nações Unidas para facilitar a transferência de informações sobre a classificação, rotulagem e embalagem de produtos químicos em todo o mundo. (EUROPA, 2017). Aqueles que desejam comercializar produtos químicos devem ser informados sobre a classificação e rotulagem fornecida pela ECHEA. As notificações são gratuitas e devem ser feitas no prazo de um mês após o lançamento do produto. Além disso, é dever do distribuidor estabelecer os riscos potenciais para a saúde humana e classificar os produtos de acordo com os riscos estabelecidos. (Europa, 2017).

Para embalagem, os regulamentos exigem que o material seja feito de um material que impeça o vazamento e seja resistente ao contato com produtos químicos, e que contenha uma vedação forte, rígida e selável (Europa, 2017). Reich/IT é um sistema de informações criado para permitir que a indústria, os membros do estado e as agências químicas europeias transmitam e processem dados e documentos com segurança (Europa, 2017). É claro que entender a gestão adequada e embalagens vazias é fundamental para cumprir a legislação.

Com base no Relatório de Sustentabilidade 2016 do INPEV, este é referência no campo da prática sustentável e membro da CropLife Latin America, organização que defende a produtividade agrícola e a sustentabilidade. O Programa de Reciclagem de Embalagens garante redução na geração de resíduos sólidos, redução no uso de matéria-prima e geração de novos empregos (Inpev, 2016). O instituto tem parcerias com cerca de 103 fabricantes (dados de 2017), comerciantes e importadores de defensivos agrícolas, cerca de 260 associações de distribuidores e cooperativas em todo o Brasil e nove organizações que representam o setor agrícola. Desde 2002, mais de 450.000 toneladas de EVA foram removidas do meio ambiente até 2017 (INPEV, 2017).

Informações como quantidade e tipo de materiais manuseados e documentação das unidades, como licenças e aprovações ambientais, podem ser monitoradas por meio do sistema de informações da bolsa (SIC). O SIC monitora a movimentação dos dados (estoque e pedidos de coleta) e processa a rastreabilidade do processo (Inpev, 2016).

As embalagens são basicamente divididas em dois grupos: laváveis e não laváveis (INPEV, 2016). A lavável é rígida e ajuda a embalar formulações líquidas diluídas em água. Podem ser de plástico, metal ou vidro. As de plástico são classificadas da seguinte forma. Polietileno de Alta Densidade que é de resina resistente a choques e produtos químicos. Leva uma numeração 2 e é a segunda resina reciclada do mundo. COEX: possui número de identificação 7 . Polipropileno: Identificado pela sigla PP e número 5.

As embalagens não laváveis não são recicláveis e representam cerca de $5 \%$ de todos os produtos do mercado. São aqueles que não utilizam água como meio de pulverização e são embalagens flexíveis ou secundárias. Exemplo: misturado ou fabricado com plástico, papel, sacolas metalizadas, outro material flexível. Embalagem de Produtos de Processamento de Sementes; embalagens termoformadas que contêm caixas de papelão ondulado, cartuchos de papelão, fibratos e, ainda assim, embalagens primárias e que não entram em contato direto com pesticidas (Inpev, 2016).

Apesar dos números serem empolgantes quanto a aplicação da logística reversa, é evidente que este numero não traduz a realidade. Isto porque as pesquisas efetuadas pelo INPEV, levaram em consideração a logística efetuada pelos grandes produtores rurais, que são aqueles economicamente capazes de proceder a devolução das embalagens vazias de agrotóxicos.

Ocorre que no Brasil, a grande concentração de agrotóxicos está nos pequenos produtores rurais, que é a maioria no Brasil.

Logo, os números apontados, apesar de animadores, não representam a realidade, de modo que a logística reversa não tem sido aplicada de forma efetiva 


\section{Desafios de Implantação}

Apesar de ter um conceito brilhante que o sistema da logística reversa possui, o que se percebe é que ela não é efetiva, pois há grandes falhas em seu processo reverso.

Conforme estudos feitos por Lopes (2017), pode se notar que uma grande parte das cidades do interior possuem falta de incentivos dos órgãos que são responsáveis pela coleta de embalagens vazias. Mesmo especificando os procedimentos adequados para descarte dessas embalagens, não realizam os investimentos adequados para sua implementação na prática como cursos e outras medidas de conscientização e também de ajuda. Ficam restritos apenas a multas e punições. No cotidiano do agricultor a medida é inviável, uma vez que a maioria das propriedades rurais são distantes dos postos de coletas.

Além disto, não rara as vezes os produtores rurais não possuem local adequado para efetuar a tríplice lavagem, bem como, não possuem local adequado para fazer o armazenamento destas embalagens, e sequer veículo apropriado para efetuar o transporte até o posto de coleta (Marques,2016).

De acordo com Braga e Romaniello (2008), o local de recebimento destas embalagens não são próximos das propriedades rurais, de modo que, há um desestímulo por parte do produtor rural ao efetuar a devolução das embalagens a cada compra, já que muitas vezes estes produtores não possuem local adequado para o armazenamento das embalagens vazias de agrotóxicos.

A consequência destes fatos é o descarte incorreto.

Cometti e Alves (2010) apontam o problema da distância entre a estação de recebimento do agricultor e a parte central e a falta de aprovação do local de recebimento. Como remédio, os autores sugerem encorajar a coleta de patrulhamento em pequenas instalações localizadas longe de postos e centros de recepção. Fortalecer os padrões de licença ambiental de instalações comerciais para recebimento de embalagens de agrotóxicos e armazenamento temporário e aumentar o monitoramento sob o fabricante, coletar em instalações comerciais licenciadas, facilitar o transporte.

Com base nesses estudos realizados por Lopes, pode se constatar também que um dos principais pontos que causar dificuldade de implantação de uma logística reversa é a estrutura por parte dos produtores e igualmente dos comerciantes. Além, da falta de fiscalização adequada do poder público, sendo clara a existência de dúvidas por parte tanto do agricultor quanto de funcionários públicos (Lopes, 2017).

Gedecke (2015), sua pesquisa, demonstra que a cadeia logística reversa não é dependente somente e a gente instituições em suas ações isoladas, demandando também uma sinergia dessas ações, onde cada elemento da cadeia opera de uma forma organizada sistematizada. Os agricultores devem fazer a sua parte, sendo as revendas através de parceria da associação com a instituição INPEV, que orienta e apoia operacionalmente. Além de ser imprescindível a fiscalização dos órgãos públicos para o funcionamento adequado do sistema e a constante pouquinho está de melhorias que são necessárias ainda.

Ocorre que, impuseram uma taxa aos comerciantes, para o credenciamento com o INPEV para que possam arrecadas as embalagens recebidas, onerando ainda mais os comerciantes. (Marques, 2016).

Cumpre destacar ainda que segundo Marques, 2016, o INPEV não possui qualquer controle efetivo de todas as embalagens recebidas, até porque, não possuem sistema integrados de todas as cidades para conferir o que foi vendido, devolvido e arrecadados.

Dentre esses desafios ao número muito grande de embalagens que não volto para a logística reversa. A também um percentual muito grande de embalagens contaminadas pelas unidades de recolhimento. Há que se ressaltar ainda, aqueles 
produtos de agrotóxicos que foram comercializados ilegalmente, os piratas, os comercializados sem receituário agronômico assim como existem muitos produtos sem nota fiscal como foi constatado pelo autor (GEDECKE, 2015).

O referido autor sugere aumento nos investimentos em programas para educação ambiental do agricultor e também da população, bem como a necessidade de fiscalização na importação de novos produtos no mercado brasileiro; controle mais rígidos em relação a revendas de embalagens vazias dentre outros

Um estudo de Macedo et al (2015) o processo de pesquisa reversa é bastante difundido nas organizações pesquisadas, mas de acordo com os resultados dos representantes uma das organizações, ainda há espaço para melhorias, pois não há necessidade de compra de agrotóxicos e isso leva a definição de ilegalidade. $\mathrm{O}$ tratamento adequado das embalagens vazias de agrotóxicos e seu retorno para minimizar a poluição ambiental aumenta a consciência ambiental, aumenta a segurança no manuseio dessas embalagens, sendo lançadas em campos e rios, causando poluição, não podendo ser utilizadas para armazenamento de outros produtos.

Deste modo, resta claro e evidente que a logística reversa é falha, pois onera o hipossuficiente, burocratiza e impõe taxas aos comerciantes, não há fiscalização e sequer acordos setoriais para fluir a logística reversa.

Em muitos casos, os pequenos produtores desconhecem os passos que realizam para o destino correto dessas embalagens e os descartam de forma inadequada. Portanto, muito investimento deve ser feito na consciência para que os usuários possam devolvê-lo imediatamente após o uso (Macedo et al 2015).

Logo, propõe-se que para que a logística reversa seja efetiva, deve ser ela viável á todos os integrantes da cadeia do agronegócio, mais precipuamente ao produtor rural, que tem um encargo maior neste ciclo reverso.

Deste modo, poderia o Poder Público, viabilizar os postos de coletas mais próximos das unidades rurais, bem como efetuar as coletas itinerantes, fomentando assim, a logística reversa.

Além disto, fomentar a logística reversa efetuando acordo setoriais com os comerciantes, para que não arquem com mais pagamento de taxas, além de auxiliar no local adequado para o armazenamento destas embalagens.

Ainda se propõe um incentivo fiscal, a aqueles que efetuarem a logística reversa, por meio de políticas públicas. E por fim, reforçar conscientização de todos para que possamos ter um meio ambiente adequado e sustentável.

\section{Considerações Finais}

Este artigo buscou discutir os principais desafios existentes no Brasil para implantação de uma adequada logística reversa no mercado brasileiro. Buscou compreender os desafios através da análise de algumas pesquisas empíricas, ancorando esta análise na leitura da contribuição teórica de diversos autores e da análise de legislação pertinente.

Pode se constatar na análise da contribuição de vários autores tanto em pesquisas empíricas quanto na contribuição mais teórica que o principal desafio é construir um processo eficaz na logística reversa, além da efetiva conscientização. Esse tema da conscientização foi mencionado por todas as pesquisas empíricas que foram analisadas, estando presente também nas outras pesquisas que foram encontradas mas não necessariamente utilizadas neste trabalho.

Constata-se que a logística reversa é necessária para uma gestão adequada e sustentável do meio ambiente. Constatase, ainda, que há muitas falhas na logística reversa, de modo que atualmente ela não se mostra viável a todos os integrantes da cadeia do agronegócio.

Neste sentido, recomenda-se estudos que analisem a integração da norma e todos os agentes ligados à cadeia da logística reversa, bem como um estudo aprofundado de como a logística reversa pode ser menos onerosa ao produtor rural e consequentemente mais efetiva. 
Research, Society and Development, v. 10, n. 2, e52210212921, 2021

(CC BY 4.0) | ISSN 2525-3409 | DOI: http://dx.doi.org/10.33448/rsd-v10i2.12921

Além disto, recomenda-se um estudo sobre as omissões da legislação da logística reversa de embalagens vazias de agrotóxicos e possíveis soluções para a sua efetividade.

\section{Referências}

Abreu, Pedro Henrique Barbosa de; Alonzo, \& Herling Gregorio Aguilar. (2016). O agricultor familiar e o uso (in) seguro de agrotóxicos no município de Lavras/MG. Recuperado de: http://www.scielo.br/scielo.php?script=sci_arttext\&pid=S030376572016000100211\&lng=en\&nrm=iso.

Borsoi, A.; Santos, P. R. R.; Taffarel, L.E.; \& Junior, A.C. G. (2014) Agrotóxicos: histórico, atualidades e meio ambiente. 16f. Programa de Pós-graduação em Agronomia- Universidade Estadual do Oeste do Paraná-Campus Marechal Cândido Rondon- Centro de Ciências Agrárias doi: $2316-4093$.

Brasil. (1984). Lei no 24.114, de 12 de abril de 1984. Recuperado de: Brasil. (2010). Lei no 12.305, de 2 de agosto de 2010. Recuperado de: http://www.planalto.gov.br/ccivil_03/_ato2007-2010/2010/lei/112305.htm

Brasil. (1989) Resolução CONAMA no 465, de 05/12/2014. Regulamenta a Lei no 7.802 , de 11 de julho de 1989. http://www.planalto.gov.br/ccivil_03/decreto/2002/D4074.htm.

BRASIL.(2014). Resolução/CONAMA 465, de 05/12/2014. Recuperado de: http://www2.mma.gov.br/port/conama/legiabre.cfm?codlegi=710.

Resolução/Resolução

$4074 / 2002$.

Recuperado

de:

http://www.planalto.gov.br/ccivil_03/decreto/2002/d4074.htm\#: :text=IV\%20\%2D\%20conceder\%20o\%20registro\%2C\%20inclusive,e\%20Abastecimento\%2 $0 \mathrm{e} \% 20 \mathrm{da} \% 20 \mathrm{Sa} \% \mathrm{C} 3 \%$ BAde.

Brasil. (2010). Lei no 12.305, de 2 de agosto de 2010. Recuperado de: http://www.planalto.gov.br/ccivil_03/_ato2007-2010/2010/lei/112305.htm

Brasil. (2000). Lei no 9.974/2002, de 06 de junho de 2002. Recuperado de: http://www.planalto.gov.br/ccivil_03/leis/19974.htm.

Brasil. (1989). Lei 7.802, de 11 de julho de 1989. Lei Agrotóxico Recuperado de: http://www.planalto.gov.br/ccivil_03/leis/L7802.htm.

Beite, P. R., Brito, E. Z., Macau, F., \& Póvoa, A. (2005). O papel dos ganhos econômicos e de imagem corporativa na estruturação dos canais reversos. GESTÃO.Org - Revista Eletrônica de Gestão Organizacional, 4(4), 227-245.

Carvalho, J. M. C. (2005). Logística. (3. ed.). Edição Sílabo.

Cometti, José Luís Said; Alves, Isabel Teresa Gama.(2010). Responsabilização Pós-Consumo e Logística Reversa: O Caso das Embalagens de agrotóxicos no Brasil. Sustentabilidade em debate. http://periodicos.unb.br/index.php/sust/article/view/727.

Creswell JW. (2010). Projeto de pesquisa: métodos qualitativo, quantitativo e misto. $3^{\text {a }}$ ed. Porto Alegre (RS). https://doi.org/10.26512/les.v13i1.11610

Europa. Your Europe. (2017). Product requirements. Classification, labelling, packaging. 2017. http://europa.eu/youreurope/business/product/chemicalspackaging-labelling-classification/index_en.htm.

Godecke, M. V. (2015). Logística reversa de embalagens de agrotóxicos: estudo do caso de pelotas/RS. Revista Meio Ambiente e Sustentabilidade | 9(4), | jul - dez 2015.

Gerassi, P.V.M. (2004). Manual de destinação final de embalagens vazias de produtos fitossanitários. http://www.fiocruz.br/biosseguranca/Bis/manuais/residuos/Manual\%20de\%20Destinacao\%20de\%20Residuos\%20Fitosanitarios.pdf.

Instituto Nacional de Processamento de Embalagens Vazias (2016). http://www.inpev.org.br/relatorio-sustentabilidade/2016/pdf/inpEV_RS2016.pdf.

Lacerda, L. (2002) Logística reversa: uma visão sobre os conceitos básicos e as práticas operacionais. http://www.sargas.com.br/site/index.php?option=com_content\&task=view\&id=78\&Itemid=2 9 .

Ladeira, Wagner Juniro; Maehker, Alisson Eduardo e Nascimento. Luis Felipe Machado. Logística reversa de defensivos agrícolas: fatores que influenciam na consciência ambiental de agricultores gaúchos e mineiros. Recuperado de: https://www.scielo.br/scielo.php?pid=SO10320032012000100009\&script=sci_abstract\&tlng=pt

Leite, P. R. (2005). Logística Reversa: Meio Ambiente e Competitividade. Pearson Prentice Hall.

Leite, P. R. (2010). Logística Reversa e a Política Nacional de Resíduos Sólidos. Revista Tecnologística. São Paulo, p. $90-92$.

Leite, P. R. (2009). Logística Reversa: meio ambiente e competitividade. São Paulo: Prentice Hall.

Liva, P. B. G. (2003). Logística Reversa. In: Gestão e Tecnologia Industrial. IETEC.

Lopes, C. L.. (2017). Implantação da Logística Reversa de Embalagens de Agrotóxico Vazias: Um Estudo em Uma Pequena Propriedade Rural do Noroeste Paulista. Revista Conbrad Maringá, 2(1), 195-215, 2017.

Ludke, M.; \& Andre, M. E. D. A. (2013). Pesquisa em educação: uma abordagem qualitativa. (2.ed.) EPU, https://repositorio.ufsm.br/bitstream/handle/1/15824/Lic_Computacao_Metodologia-Pesquisa-Cientifica.pdf?sequence=1. 
Research, Society and Development, v. 10, n. 2, e52210212921, 2021

(CC BY 4.0) | ISSN 2525-3409 | DOI: http://dx.doi.org/10.33448/rsd-v10i2.12921

Marques, M. D. (2015). Discussão da Estrutura Formal Sobre o Retorno das Embalagens de Agrotóxicos: uma Revisão Teórica sob os aspectos legais e da Consciência Ambiental. Periódico Eletrônico Fórum Ambiental da Alta Paulista, [S.1.], 11(2), out. $2015 . \quad$ ISSN $1980-0827$. http://www.amigosdanatureza.org.br/publicacoes/index.php/f orum_ambiental/article/view/1085.

Marques, V., Marques Junior, M. D.; Silvia C. V., \& Braga Junior, S. S. (2016). A Logística Reversa de Embalagens Vazias de Agrotóxicos junto a produtores $\begin{array}{llllll}\text { rurais } & \text { do Interior } & \text { do } & \text { Estado } & \text { de } & \text { São }\end{array}$ file:///C:/Users/crema/Documents/Mestrado/Disserta\%C3\%A7\%C3\%A3o/Material\%20de\%20Apoio/Artigo\%20S\%C3\%A9rgio.pdf.

Marques, M. D. (2016). Logística reversa de embalagens de agrotóxicos: uma análise da região da Alta Paulista. Dissertação (Mestrado) Universidade Estadual Paulista "Júlio de Mesquita Filho". Tupã.

Macedo, L. R. (2015). Logística reversa das embalagens de agrotóxicos na associação das revendas de defensivos agrícolas da região centro do estado do rio grande do sul (ARDEC). XXXV Encontro Nacional De Engenharia De Producao Perspectivas Globais para a Engenharia de Produção Fortaleza, CE, Brasil.

Rogers, Dr. Dale S.; Tibben-Lembke, Dr. Ronald S. \& Going Backwards. (1998): Reverse Logistics Trends and Practices. http://www.abrelpe.org.br/imagens_intranet/files/logistica_reversa.pdf.

Sehnem, S. et al. (2009). Gestão e estratégia ambiental:um estudo bibliométrico sobre o interesse do tema nos periódicos acadêmicos brasileiros. REA Revista Eletrônica de Administração,72. ed., n. 2.

Souza, A. (2011). Avaliação do impacto da exposição a agrotóxicos sobre a saúde de população rural: Vale do Taquari (RS, Brasil). http://www.scielo.br/scielo.php?script=sci_arttext\&pid=S141381232011000900020\&lng=pt\&nrm=iso.

Schmidt; MLG; Godinho, P.H. Um breve estudo acerca do cotidiano do trabalho dos produtores rurais: intoxicações por agrotóxicos e subnotificação. Recuperado de: https://www.scielo.br/pdf/rbso/v31n113/04.pdf.

Soares, W. L.; Freitas, E. A. V. de; \& Coutinho, J. A. G. (2005). Trabalho rural e saúde: intoxicações por agrotóxicos no municipio de Teresópolis. http://www.scielo.br/scielo.php?script=sci_arttext\&pid=S0103- 20032005000400004\&lng=en\&nrm=isso 